\title{
Substituição do milho pela glicerina em suplementos múltiplos para novilhos Nelore em pastejo
}

\section{Replacement of corn by glycerin in multiple supplements for Nellore steers on pasture}

\author{
Renata Pereira da Silva-Marques ${ }^{1 *}$; Joanis Tilemahos Zervoudakis ${ }^{2}$; \\ Luciana Keiko Hatamoto-Zervoudakis ${ }^{2}$; Luciano da Silva Cabral'; \\ Emerson Alexandrino ${ }^{3}$; Antônio José Neto ${ }^{4}$ Jefferson Fabiano Werner Koscheck ${ }^{4}$; \\ Lilian Chambó Rondena Pesqueira Silva ${ }^{4}$; Rafael Ferrato Gonçalves da Silva ${ }^{5}$
}

\section{Resumo}

\begin{abstract}
Objetivou-se avaliar o desempenho produtivo e os custos de produção de novilhos Nelore recriados em pastagem de Brachiaria brizantha cv. Marandu durante o período seco do ano recebendo suplemento mineral e suplementos com substituição parcial do milho por glicerina residual bruta. Foram utilizados 40 novilhos Nelore com peso corporal médio inicial de 203,12 $\pm 20,10 \mathrm{~kg}$ e idade média inicial de 12 meses, distribuídos em oito piquetes de 1,6 ha cada. O delineamento foi inteiramente casualizado com oito suplementos e cinco repetições. Foram avaliados suplementos com níveis de substituição parcial do milho por glicerina: $0 \%(\mathrm{G} 0)$; $10 \%$ (G10); 20\% (G20); 30\% (G30); 40\% (G40); 50\% (G50) e 60\% (G60), fornecidos na quantidade de $1 \mathrm{~kg} / \mathrm{animal} / \mathrm{dia}$ na matéria natural, além de um suplemento mineral ad libitum $(\mathrm{SM})$. $\mathrm{O}$ ganho médio diário $(\mathrm{GMD})$ foi maior $(\mathrm{P}<0,05)$ em animais recebendo os suplementos G30 $(0,609 \mathrm{~kg}), \mathrm{G} 40(0,588 \mathrm{~kg})$ e $\mathrm{G} 60(0,611 \mathrm{~kg})$ em relação aos suplementos G0 $(0,546 \mathrm{~kg}), \mathrm{G} 10$ $(0,509 \mathrm{~kg}), \mathrm{G} 50(0,561 \mathrm{~kg})$ e $\mathrm{SM}(0,223 \mathrm{~kg})$. Os animais suplementados apresentaram maior GMD $(\mathrm{P}<0,05)$ em relação ao SM. Os diferentes níveis proporcionaram retorno financeiro positivo. Concluise, que o fornecimento de suplementos múltiplos substituindo o milho por glicerina em sistemas de produção de novilhos de corte no período da seca proporciona maior desempenho produtivo nos níveis de 30,40 e $60 \%$ e retorno financeiro positivo até níveis de $60 \%$ de substituição, demonstrando, portanto, o seu potencial de uso em sistemas intensivos de produção de carne bovina a pasto.
\end{abstract}

Palavras-chave: Bovinos de corte, custo de produção, recria, suplementação

\footnotetext{
Abstract

The objective was to evaluate the performance and production costs of Nellore steers growing on Brachiaria brizantha $\mathrm{cv}$. Marandu during the dry season receiving mineral supplements with partial replacement of corn by residual glycerin. 40 Nellore steers with initial body weight of $203.12 \pm 20.10$ $\mathrm{kg}$ and average initial age of 12 months, distributed into eight paddocks of 1.6 ha each, were used.

${ }^{1}$ Discente de Doutorado em Ciência Animal, Universidade Federal de Mato Grosso, UFMT, Cuiabá, MT. E-mail: renatinharps@, hotmail.com

${ }^{2}$ Profs. Drs., Universidade Federal de Mato Grosso, UFMT, Cuiabá, MT. E-mail: joanis@ufmt.br; lukeiko@yahoo.com.br; cabralls@ufmt.br

3 Prof. Dr., Universidade Federal do Tocantins, UFT, Araguaína, TO. E-mail: e alexandrino@yahoo.com.br

${ }^{4}$ Discentes de Doutorado em Zootecnia, Universidade Estadual Paulista, UNESP, Jaboticabal, SP. E-mail: antoniojoseneto@ yahoo.com.br; jeffersonfwk@hotmail.com; lilianrondena@hotmail.com

${ }^{5}$ Médico Veterinário, Cuiabá, MT. E-mail: rafaelgfsmedvet@yahoo.com.br

* Autor para correspondência
} 
The experimental design was completely randomized with five replicates and eight supplements. Supplements with levels of partial replacement of corn by glycerin were evaluated: $0 \%(\mathrm{G} 0), 10 \%$ (G10), 20\% (G20), 30\% (G30), 40\% (G40), 50\% (G50) and 60\% (G60) provided on the amount of 1 $\mathrm{kg} /$ animal/day in the natural matter, and a mineral supplement (MS). The average daily gain (ADG) was higher $(\mathrm{P}<0.05)$ in animals receiving supplements $\mathrm{G} 30(0.609 \mathrm{~kg}), \mathrm{G} 40(0.588 \mathrm{~kg})$ and $\mathrm{G} 60$ $(0.611 \mathrm{~kg})$ in relation to supplements G0 $(0.546 \mathrm{~kg}), \mathrm{G} 10(0.509 \mathrm{~kg}), \mathrm{G} 50(0.561 \mathrm{~kg})$ and MS $(0.223$ $\mathrm{kg})$. There were differences $(\mathrm{P}<0.10)$ in ADG in supplemented animals when compared to MS. The supplemented animals showed higher ADG $(\mathrm{P}<0.05)$ compared to MS. The different levels provided positive financial return. It is concluded that the supply of multiple supplements replacing the corn by glycerol in production systems of steers in the dry period provides higher productive performance levels of 30,40 and $60 \%$ and positive financial return to levels of $60 \%$ of replacement, demonstrating thus, its potential use for intensive systems of beef production on pasture.

Key words: Beef cattle, production cost, growing, supplementation

\section{Introdução}

$\mathrm{O}$ aumento na oferta de concentrados oriundos da agroindústria é inevitável, uma vez que o crescente aumento da produção de biodiesel gera uma série de coprodutos passíveis de utilização na alimentação de ruminantes. Sendo assim, na pecuária globalizada, os planos nutricionais para bovinos de corte em pastejo são cada vez mais baseados em alternativas suplementares para melhor ajuste da dieta fornecida às exigências nutricionais dos animais.

Sabendo-se que a alimentação, independente da atividade e/ou do produto, ainda é o item de maior peso no custo final, as indústrias do setor têm-se preocupado constantemente em buscar formas para diminuir os custos de produção. Desse modo, alimentos alternativos vêm sendo estudados e avaliados quanto aos aspectos econômicos e nutricionais, para que possam viabilizar a produção intensiva de ruminantes suplementados com menores custos de produção (ZERVOUDAKIS et al., 2011a).

Os principais coprodutos do biodiesel são obtidos após a extração do óleo de sementes de oleaginosas, constituindo as tortas e os farelos, e após o processo de conversão de triglicerídeos em biodiesel por meio de transesterificação (glicerina bruta), os quais, em conjunto, representam mais de $50 \%$ da massa inicial de sementes utilizadas na cadeia agroindustrial (ZERVOUDAKIS et al., 2011b).
A glicerina tem sido utilizada com sucesso na alimentação de suínos (LAMMERS et al., 2008) e aves (CERRATE et al., 2006) e tem sido considerada como fonte alimentar energética alternativa e promissora na produção animal. $\mathrm{O}$ potencial da glicerina na alimentação animal é baseado no fato de ser uma substância glicogênica similar ao propilenoglicol, o qual tem sido utilizado com eficiência desde 1954 na prevenção de cetose em vacas de alta produção de leite por aumentar o suprimento de precursores da glicose (SAUER; ERFLE; FISHER, 1973). Sendo assim, a glicerina tem surgido como potencial substituto da fonte tradicional de energia (milho), visando redução nos custos de produção (PARSONS; SHELOR; DROUILLARD, 2008).

Deste modo, objetivou-se avaliar o desempenho produtivo e os custos de produção de novilhos de corte em pastejo no período seco do ano, recebendo suplementos múltiplos com diferentes níveis de substituição do milho pela glicerina.

\section{Material e Métodos}

O experimento foi conduzido no setor de Bovinocultura de Corte da Fazenda Experimental da Faculdade de Agronomia, Medicina Veterinária e Zootecnia - FAMEVZ da Universidade Federal de Mato Grosso - UFMT, no período da seca. O clima da região é do tipo Aw de acordo com a classificação 
Köppen, ou seja, clima tropical, megatérmico, com inverno seco e chuvas no verão (Tabela 1$)$.

Foram utilizados 40 novilhos Nelore com peso corporal médio inicial de $203,12 \pm 20,10 \mathrm{~kg}$ e idade média inicial de 12 meses, mantidos em oito piquetes de 1,6 ha cada, cobertos uniformemente com Brachiaria brizanha cv. Marandu, providos de bebedouros e cochos cobertos para fornecimento do suplemento, cujas dimensões permitiram acesso de todos os animais simultaneamente. Visando reduzir a influência de possíveis variações de ambiente, cada lote permaneceu em cada piquete por 7 dias procedendo-se, ao final desse período, à rotação entre eles. Ao início do experimento, todos os animais foram submetidos ao controle de endo e ectoparasitas.

Tabela 1. Valores médios das temperaturas máximas e mínimas, umidade relativa do ar e precipitação pluviométrica, coletadas durante o período experimental.

\begin{tabular}{|c|c|c|c|c|}
\hline \multirow{2}{*}{ Meses } & \multicolumn{2}{|c|}{ Temperatura média $\left({ }^{\circ} \mathrm{C}\right)$} & \multirow{2}{*}{$\begin{array}{l}\text { Umidade Relativa } \\
\text { do ar }(\%)\end{array}$} & \multirow{2}{*}{ Precipitação (mm) } \\
\hline & Máxima & Mínima & & \\
\hline Julho & 32,7 & 16,0 & 69,0 & 1,1 \\
\hline Agosto & 35,5 & 17,2 & 58,2 & 10,9 \\
\hline Setembro & 35,8 & 20,8 & 52,7 & 5,6 \\
\hline Outubro & 35,4 & 22,5 & 64,5 & 40,9 \\
\hline
\end{tabular}

Fonte: Estação Agrometeorológica Padre Ricardo Remetter - Fazenda Experimental UFMT.

Os suplementos (Tabela 2) foram formulados com níveis de substituição parcial do milho pela glicerina, com fornecimento diário de $1 \mathrm{~kg} / \mathrm{animal}$, às 10 horas da manhã, monitorando-se as sobras de suplementos e o fornecimento do suplemento mineral foi ad libitum aos animais.

Tabela 2. Composição alimentar do concentrado fornecido aos animais.

\begin{tabular}{|c|c|c|c|c|c|c|c|c|c|}
\hline \multirow{2}{*}{ Ingredientes } & \multirow{2}{*}{$\mathrm{SM}^{\mathrm{a}}$} & \multicolumn{7}{|c|}{ Substituição do Milho pela Glicerina (MN) ${ }^{1}$} & \multirow{2}{*}{$\mathrm{R} \$ / \mathrm{kg}$} \\
\hline & & $\mathrm{G} 0^{2}$ & $\mathrm{G} 10^{2}$ & $\mathrm{G} 20^{2}$ & $\mathrm{G} 30^{2}$ & $\mathrm{G} 40^{2}$ & $\mathrm{G} 50^{2}$ & $\mathrm{G} 60^{2}$ & \\
\hline Milho grão triturado & - & 40,00 & 35,99 & 31,98 & 27,97 & 23,95 & 19,94 & 15,93 & 0,37 \\
\hline Farelo soja & - & 48,00 & 48,00 & 48,00 & 48,00 & 48,00 & 48,00 & 48,00 & 0,50 \\
\hline Uréia: Sulfato de Amônia 9:1 & - & 6,00 & 6,01 & 6,02 & 6,03 & 6,05 & 6,06 & 6,07 & 1,85 \\
\hline Mistura mineral & - & 6,00 & 6,00 & 6,00 & 6,00 & 6,00 & 6,00 & 6,00 & 1,17 \\
\hline Glicerina & - & - & 4,00 & 8,00 & 12,00 & 16,00 & 20,00 & 24,00 & - \\
\hline Total & 100,0 & 100,0 & 100,0 & 100,0 & 100,0 & 100,0 & 100,0 & 100,0 & - \\
\hline
\end{tabular}

aSM- Suplemento mineral comercial: Níveis de garantia: cálcio 198g; fósforo 87g; sódio 97,6g; magnésio 5,1g; enxofre 12g; iodo $17,7 \mathrm{mg}$; ferro $280 \mathrm{mg}$; selênio $18 \mathrm{mg}$; cobalto $80 \mathrm{mg}$; manganês $527 \mathrm{mg}$; flúor $870 \mathrm{mg}$; cobre $1.250 \mathrm{mg}$ e zinco $3.500 \mathrm{mg} . \%$; ${ }^{1}$ Matéria natural; ${ }^{2}$ Níveis de substituição parcial do milho pela glicerina: $0,10,20,30,40,50$ e $60 \%$, respectivamente.

Fonte: Elaboração dos autores.

Os animais foram pesados no início e final do experimento após serem submetidos a jejum de sólidos de 14 horas. Após a pesagem inicial os animais foram estratificados com base no peso corporal (PC) e distribuídos em lotes com pesos semelhantes.

$\mathrm{O}$ experimento foi estruturado em delineamento inteiramente casualizado (DIC), sendo constituído de quatro períodos experimentais de 28 dias cada, 
perfazendo um total de 112 dias, sendo que o ganho médio diário e o ganho de peso corporal foram determinados pela diferença entre o peso final e o inicial, com jejum prévio. A cada 28 dias foram realizados pesagem sem jejum dos animais.

No primeiro dia de cada período experimental foram realizadas coletas de amostras de forragem nos diferentes piquetes, através do corte, a $5 \mathrm{~cm}$ do solo, de três áreas delimitadas por um quadrado metálico de 0,5 x 0,5 m, escolhidos na altura média da forragem (50 pontos em cada diagonal, totalizando 100 pontos de altura mensurados por piquete) para a estimação da massa de forragem e a matéria seca potencialmente digestível (MSpD), conforme recomendações do Instituto Nacional de Ciência e Tecnologia - Ciência Animal (INCT - CA).

Após a coleta, as amostras de cada piquete foram pesadas e homogeneizadas, e a partir dessas retiradas duas alíquotas compostas: uma para avaliação da massa de forragem (MF)/ha e a outra para fracionamento dos componentes estruturais da planta e posterior análise das disponibilidades por hectare de matéria seca de lâmina foliar verde, lâmina foliar seca, pseudocolmo verde e pseudocolmo seco. A amostragem da forragem consumida pelos animais foi obtida via simulação manual do pastejo, realizada no $1^{\circ}$ dia de cada período experimental. As amostras foram imediatamente pesadas após as coletas e congeladas a $-20^{\circ} \mathrm{C}$, e posteriormente, descongeladas e secas em estufa de ventilação forçada a $65{ }^{\circ} \mathrm{C}$, moídas em moinho tipo Willey (com peneira de malha de 1,0 $\mathrm{mm}$ ), para posterior analises químico-bromatológicas.

Das amostras destinadas à estimativa da MF, foi determinado o resíduo insolúvel em detergente neutro avaliado após incubação in situ das amostras por 240 horas (FDNi) (CASALI et al., 2008), para cálculo do percentual de MS potencialmente digestível (MSpD) disponível aos animais.

As amostras dos ingredientes, suplementos e forragens foram analisadas para determinação dos teores de matéria seca (MS), matéria mineral
(MM), matéria orgânica (MO), proteína bruta (PB) e extrato etéreo (EE) de acordo com Silva e Queiroz (2002). As avaliações da fibra em detergente neutro (FDN), fibra em detergente neutro corrigida para cinzas e proteína (FDNcp), fibra em detergente ácido (FDA) conforme protocolo descrito por Van Soest, Robertson e Lewis (1991).

Os carboidratos totais (CT) das amostras foram calculados segundo metodologia descrita por Sniffen et al. (1992), em que CT(\%) = 100 - (\%PB + $\%$ EE $+\%$ Cinzas). A quantificação de carboidratos não fibrosos (CNF) dos suplementos foi realizada de acordo com adaptação de Hall (2000), em virtude da inclusão de uréia na composição dos suplementos.

Os teores de nutrientes digestíveis totais (NDT) foram estimados segundo o NRC (2001) com base na composição químico-bromatológica dos alimentos, por intermédio da equação: NDT $(\%)=$ $(\mathrm{PBD}+\mathrm{CNFD}+\mathrm{FDNpD}+\mathrm{EED} \times 2,25)-7$, onde a constante 7 refere-se ao valor metabólico fecal. Os valores de proteína bruta digestível (PBD), ácidos graxos digestíveis (AGD), fibra em detergente neutro corrigida para proteína digestível (FDNpD) e carboidratos não fibrosos digestíveis (CNFD) foram estimados de acordo com as seguintes equações (NRC, 2001):

A avaliação econômica do desempenho animal foi realizada tendo em vista a remuneração do capital investido, dividindo-se a margem de lucro pelas despesas envolvidas no processo de suplementação. A receita foi obtida através da multiplicação do ganho em equivalente carcaça (@) pelo valor da arroba na região, e as despesas foram obtidas através do custo total com suplemento. Todas as cotações empregadas foram tomadas no Estado de Mato Grosso e no período em que se conduziu este experimento.

Depois de obtidos os resultados da avaliação econômica, foram simulados possíveis cenários para estes indicadores a partir do coeficiente de variação de algumas variáveis. 
Foi feita uma simulação de possíveis cenários que podem ocorrer considerando a variação de preço da arroba do boi de $\mathrm{R} \$ 55,00$ a $\mathrm{R} \$ 110,00$, visto que a série histórica dos preços praticados entre os anos de 2007 a 2013 variaram de $\mathrm{R} \$ 53,03$ a R\$ 102,00; e variação no preço do suplemento $(\mathrm{kg})$ de $\mathrm{R} \$ 0,45 \mathrm{a}$ $\mathrm{R} \$ 1,30$, na região onde foi desenvolvida a pesquisa, por serem estas as variáveis que mais impactam no resultado da avaliação econômica nesta pesquisa.

A partir dos resultados da avaliação econômica para os suplementos em função dos resultados das médias de desempenho dos animais submetidos a cada dieta experimental, obtiveram-se as médias gerais, as quais foram submetidas às simulações dos possíveis cenários, substituindo o valor da arroba e do suplemento encontrados para cada cenário, gerando assim, seis simulações de viabilidade econômica para cada cenários, sendo eles o melhor, pior, médio, mais provável, otimista e pessimista.

O melhor cenário foi gerado considerando-se o preço máximo praticado no mercado pela arroba do boi e o preço mínimo do suplemento $(\mathrm{kg})$;

O pior cenário foi gerado considerando-se o preço mínimo praticado pela arroba e o preço máximo do suplemento $(\mathrm{kg})$;

O cenário médio foi gerado considerando-se as médias dos preços de ambas variáveis.

O cenário mais provável foi gerado considerandose os o preço das variáveis que ocorrem com maior frequência.

O cenário otimista foi gerado considerando-se as médias do preço da variável arroba do boi, adicionado do percentual do coeficiente de variação $(+21,85 \%)$ obtido a partir da série de preços coletados e ainda subtraído do coeficiente de variação $(-30,51 \%)$ da série de preços referente ao suplemento.

O cenário pessimista foi gerado considerandose as médias do preço da variável arroba do boi, subtraído do percentual do coeficiente de variação (-21,85\%) obtido a partir da série de preços coletados e ainda adicionado o percentual do coeficiente de variação $(+30,51 \%)$ da série de preços referente ao suplemento.

O lucro dos cenários foi obtido a partir do lucro dos animais suplementados subtraído ao lucro dos animais controle (suplemento mineral).

$\mathrm{O}$ experimento foi estruturado em delineamento inteiramente casualizado (DIC), em que primeiramente foi empregado a ANOVA para verificar efeito de tratamento. Observando-se efeito de tratamento foi realizado o Teste de Tukey. Os procedimentos estatísticos foram realizados por intermédio do programa SAS (Versão 9,2), adotando 0,05 como nível crítico de probabilidade.

\section{Resultados e Discussão}

A massa de forragem (MF) média foi de 3775,81 $\mathrm{kg} / \mathrm{ha}$. Com o avanço do período seco a MF foi reduzida, associada à diminuição acentuada do crescimento e avanço na maturidade das gramíneas, efeito do pastejo exercido pelos animais e senescência de componentes do dossel forrageiro. No entanto, no último período experimental observou-se aumento de $15 \%$ na massa de forragem em relação ao período anterior, em decorrência das condições climáticas favoráveis (Tabela 1). A MF (Figura 1) foi superior aos valores de 2.500 a 3.000 $\mathrm{kg} / \mathrm{MS} / \mathrm{ha}$, considerados como adequado para o período seco (EUCLIDES et al., 2000).

De acordo com Mertens (1994), o desempenho animal depende do consumo de nutrientes digestíveis totais e metabolizáveis, sendo assim, pastagens com menor massa de forragem dificultam a apreensão e a seletividade, pois o animal não tem a capacidade de colhê-la com eficiência, e isso, acarreta em desempenho insatisfatório. Isto não foi verificado neste estudo, uma vez que a MF não suprimiu a seletividade animal, pois disponibilizou elevada quantidade de nutrientes passíveis de utilização pelas bactérias ruminais, e consequentemente, proporcionaram efeito positivo no desempenho dos animais, ou seja, não limitou a resposta produtiva. 
Figura 1. Valores médios de massa de forragem (MF), matéria seca potencialmente digestível (MSpD), MS de lâmina foliar verde (MLFV), MS de lâmina foliar seca (MLFS), MS de pseudocolmo verde (MPCV) e MS de pseudocolmo seco (MPCS) de Brachiaria brizantha cv. Marandu nos períodos experimentais.

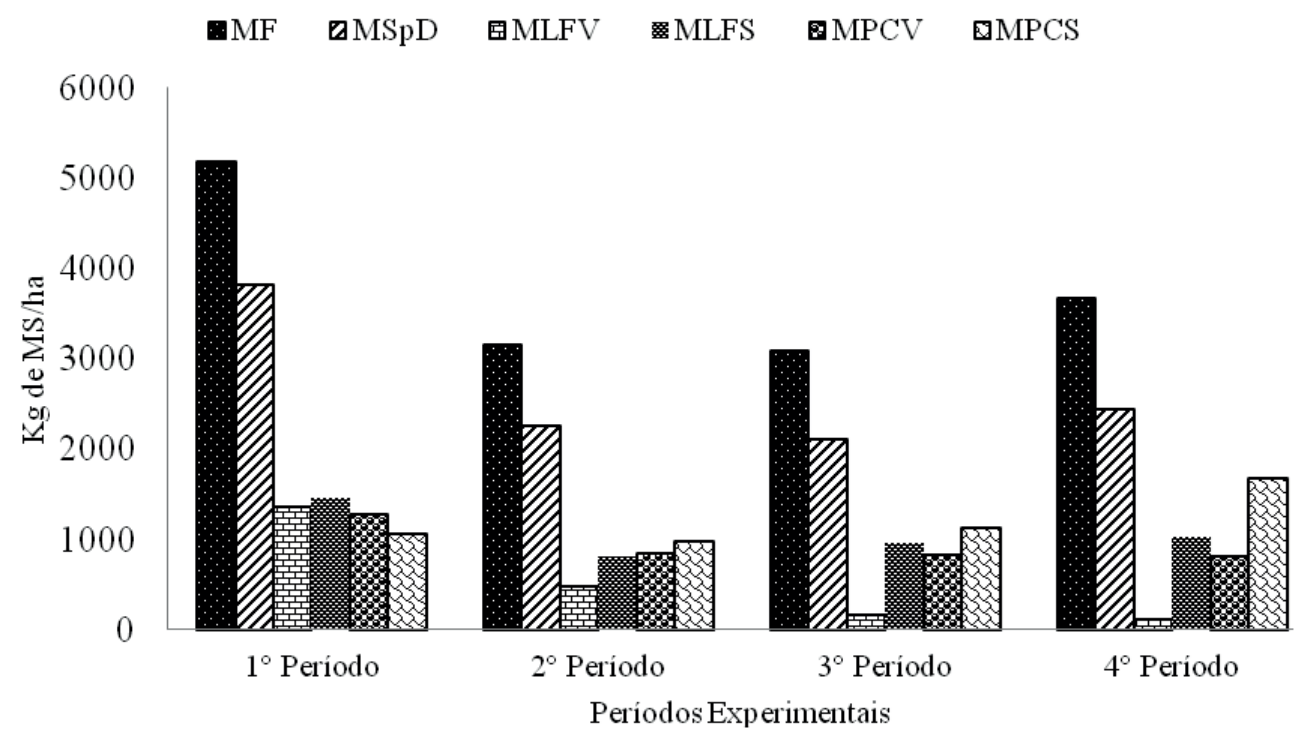

Fonte: Elaboração dos autores.

Apesar da elevada relação folha:colmo $(0,70)$ observada na forragem, as amostras de pasto obtida via simulação manual de pastejo apresentaram a quantidade de $\mathrm{PB}$ de $46,47 \mathrm{~g} / \mathrm{kg}$ de MS (Tabela
3) aquém do considerado como nível crítico para satisfazer as exigências microbianas em compostos nitrogenados (7\% PB na dieta basal) que permitem a fermentação dos carboidratos fibrosos no rúmen (REIS et al., 2005).

Tabela 3. Composição nutricional dos suplementos e da forragem.

\begin{tabular}{crrrrrrrl}
\hline \multirow{2}{*}{ Item } & \multicolumn{7}{c}{ Suplementos } & \multirow{2}{*}{ Forragem } \\
\cline { 2 - 7 } & \multicolumn{1}{c}{ G0 } & \multicolumn{1}{c}{ G10 } & \multicolumn{1}{c}{ G20 } & \multicolumn{1}{c}{ G30 } & \multicolumn{1}{c}{ G40 } & \multicolumn{1}{c}{ G50 } & \multicolumn{1}{c}{ G60 } & \\
\hline Matéria seca $^{2}$ & 843,6 & 808,1 & 772,6 & 737,2 & 701,7 & 666,3 & 630,8 & 535,0 \\
Matéria orgânica $^{3}$ & 959,7 & 960,5 & 961,3 & 962,0 & 962,8 & 963,6 & 964,4 & 89,3 \\
Matéria mineral $^{3}$ & 40,3 & 39,5 & 38,7 & 38,0 & 37,2 & 36,4 & 35,6 & 910,6 \\
Proteína bruta $^{3}$ & 446,3 & 443,0 & 439,7 & 436,4 & 433,4 & 430,1 & 426,8 & 46,47 \\
Extrato etéreo $^{3}$ & 23,6 & 22,2 & 20,7 & 19,3 & 17,9 & 16,4 & 15,0 & 20,2 \\
Carboidratos totais $^{3}$ & 528,8 & 494,5 & 460,2 & 426,0 & 391,6 & 357,3 & 323,1 & 844,0 \\
FDN $^{3}$ & 190,6 & 186,6 & 182,6 & 178,7 & 174,7 & 170,7 & 166,7 & 699, \\
FDA $^{3}$ & 111,2 & 109,9 & 108,6 & 107,3 & 106,0 & 104,7 & 103,4 & 520,0 \\
FDNcp $^{3}$ & 160,7 & 157,0 & 153,4 & 149,8 & 146,1 & 142,5 & 138,8 & 631,1 \\
FDNi $^{3}$ & 22,7 & 21,9 & 21,1 & 20,4 & 19,6 & 18,8 & 18,1 & 222,2 \\
NIDN $^{4}$ & 64,6 & 60,5 & 56,4 & 52,3 & 48,2 & 44,1 & 40,1 & 479,0 \\
NIDA $^{4}$ & 27,1 & 25,4 & 23,8 & 22,1 & 20,4 & 18,7 & 17,0 & 386,8 \\
CNF $^{3}$ & 331,4 & 302,2 & 272,9 & 243,6 & 214,3 & 185,0 & 155,7 & 212,8 \\
NDT estimados $^{3}$ & 470,3 & 479,0 & 487,7 & 496,5 & 505,1 & 513,8 & 522,6 & 537,9 \\
\hline
\end{tabular}

${ }^{1}$ (g/kg de matéria natural); ${ }^{2}$ (g/kg de matéria seca); ${ }^{3}$ (g/kg de nitrogênio total); ${ }^{4}$ Estimado segundo NRC (2001).

Fonte: Elaboração dos autores. 
Segundo Paulino et al. (2004), a digestão da parede celular das gramíneas requer uma microbiota com capacidade para digerir seus constituintes. Sendo assim, em situações em que a proteína é o principal nutriente limitante para a utilização de forrageiras tropicais de baixa qualidade, a suplementação com compostos nitrogenados é recomendada para promover condições favoráveis para o desenvolvimento e proliferação de microrganismos ruminais e melhorar a eficiência de utilização dos constituintes fibrosos da forragem (VAN SOEST, 1994).

Devido às características qualitativas (Tabela 3) e quantitativas (Figura 1) apresentadas pelo pasto, os animais responderam ao uso de suplementos múltiplos $\quad(\mathrm{P}<0,0001), \quad$ o que correspondeu ao incremento médio de 333g/animal/dia em comparação àqueles que consumiram apenas suplemento mineral (223 g/dia) (Tabela 4).

Tabela 4. Peso corporal inicial (PCi), peso corporal final (PCf), ganho médio diário (GMD) e ganho de peso corporal adicional (PCA) de novilhos na seca.

\begin{tabular}{ccccccccc}
\hline & \multirow{2}{*}{$\mathrm{SM}^{\mathrm{a}}$} & \multicolumn{7}{c}{ Suplementos } \\
\cline { 3 - 8 } & & $\mathrm{G}^{1}$ & $\mathrm{G} 10^{1}$ & $\mathrm{G} 20^{1}$ & $\mathrm{G}^{1}$ & $\mathrm{G}^{1} 0^{1}$ & $\mathrm{G} 50^{1}$ & $\mathrm{G}^{1}$ \\
\hline PCi $(\mathrm{kg})$ & 198,6 & 202,8 & 203,6 & 203,8 & 204,2 & 204,2 & 204 & 203,8 \\
PCf $(\mathrm{kg})$ & 223,6 & 263,9 & 260,6 & 256,2 & 272,4 & 270,1 & 266,8 & 272,2 \\
GMD $(\mathrm{kg} / \mathrm{dia})$ & $0,223 \mathrm{c}$ & $0,546 \mathrm{ab}$ & $0,509 \mathrm{ab}$ & $0,468 \mathrm{~b}$ & $0,609 \mathrm{a}$ & $0,588 \mathrm{a}$ & $0,561 \mathrm{ab}$ & $0,611 \mathrm{a}$ \\
PCA (kg/dia) & - & 0,32 & 0,29 & 0,24 & 0,39 & 0,36 & 0,34 & 0,39 \\
\hline
\end{tabular}

Médias seguidas de letras iguais na mesma linha não diferem estatisticamente entre si pelo Teste de Tukey ao nível de 5\% de probabilidade

${ }^{\text {aS }}$ Suplemento mineral; ${ }^{1}$ Níveis de substituição parcial do milho pela glicerina: $0,10,20,30,40,50$ e $60 \%$, respectivamente. ${ }^{2}$ Ganho diferencial em relação ao animais do suplemento mineral.

Fonte: Elaboração dos autores.

A inclusão de glicerina potencializou o desempenho dos animais suplementados, os quais apresentaram valor médio de $557 \mathrm{~g} /$ dia. Estes resultados provavelmente estão relacionados ao consumo de MS total, que possivelmente não foi influenciado pela inclusão de glicerina, tendo em vista que, a ingestão de MS é considerada o ponto determinante de aporte de nutrientes necessários para atendimento das exigências de mantença e de ganho de peso dos animais (SNIFFEN et al., 1993).

Além disso, San Vito et al. (2012) avaliaram o desempenho de novilhos Nelore $(279 \mathrm{~kg}$ ) recriados a pasto de Brachiaria brizantha cv Xaraés no período da seca, suplementados com $0 ; 7 ; 14 ; 21$ e $28 \%$ de glicerina na MS do suplemento em substituição ao milho, e concluíram que o aumento nos níveis de glicerina bruta pode aumentar o ganho de peso médio diário e peso corporal final dos animais.
Em contrapartidas a estes resultados, Farias et al. (2012) avaliaram o desempenho de novilhas (13 meses e $226 \mathrm{~kg}$ ) recriadas a pasto de Brachiaria brizantha cultivar Marandu suplementadas com níveis de inclusão de glicerina de $0 ; 2,8 ; 6,1$ e $9,0 \%$ na MS total na dieta, e verificaram redução linear no GMD e peso corporal final dos animais, e concluíram que a redução no desempenho animal pode ser explicada pela qualidade da glicerina utilizada, a qual apresentava coloração mais escura, pouco adocicada e adstringente ao paladar e aspecto oleoso, o que caracteriza a glicerina de baixa pureza.

Adicionalmente, o peso corporal final dos animais que receberam suplementação concentrada (Tabela 4) foi $18,97 \%$ superior ao daqueles do grupo controle $(\mathrm{SM})(\mathrm{P}<0,05)$, o que pode acelerar o retorno do capital total investido, devido ao menor 
tempo que os animais permanecerão na fase de recria.

O melhor desempenho foi obtido com os níveis de $30,40,50$ e $60 \%$ de substituição do milho pela glicerina. Sendo assim, a melhor resposta produtiva e o menor custo diário com a suplementação destacaram a estratégia de $60 \%$ de substituição do milho pela glicerina, como sendo a mais viável economicamente (Tabela 5).

Tabela 5. Indicadores econômicos de produção por animal para os diferentes suplementos.

\begin{tabular}{|c|c|c|c|c|c|c|c|c|}
\hline & \multirow{2}{*}{$\mathrm{SM}^{\mathrm{a}}$} & \multicolumn{7}{|c|}{ Suplementos } \\
\hline & & $\mathrm{G}^{1}{ }^{1}$ & $\mathrm{G}^{2} 0^{1}$ & $\mathrm{G} 20^{1}$ & $\mathrm{G}^{2} 0^{1}$ & $\mathrm{G}_{4} 0^{1}$ & $\mathrm{G}^{2} 0^{1}$ & $\mathrm{G}^{2} 0^{1}$ \\
\hline Consumo de Suplementos $(\mathrm{kg})^{2}$ & 0,07 & 1,00 & 1,00 & 1,00 & 1,00 & 1,00 & 1,00 & 1,00 \\
\hline Custo do suplemento R \$/kg & 1,17 & 0,57 & 0,56 & 0,54 & 0,53 & 0,51 & 0,50 & 0,48 \\
\hline Custos dos suplementos (R $\$$ dia) & 0,078 & 0,571 & 0,556 & 0,542 & 0,527 & 0,513 & 0,498 & 0,483 \\
\hline Custos suplementação (R\$/112dias) & 8,78 & 63,92 & 62,28 & 60,65 & 59,02 & 57,40 & 55,77 & 54,14 \\
\hline Peso corporal inicial $(\mathrm{kg})$ & 198,6 & 202,8 & 203,6 & 203,8 & 204,2 & 204,2 & 204 & 203,8 \\
\hline Peso corporal final (kg) & 223,6 & 264 & 260,6 & 256,2 & 272,4 & 270 & 266,8 & 272,2 \\
\hline Ganho de peso corporal (kg/112dias) & 25,00 & 61,20 & 57,00 & 52,40 & 68,20 & 65,80 & 62,80 & 68,40 \\
\hline Ganho médio diário $(\mathrm{kg} / \mathrm{dia})$ & 0,223 & 0,546 & 0,509 & 0,468 & 0,609 & 0,588 & 0,561 & 0,611 \\
\hline Peso corporal adicional $(\mathrm{kg} / \mathrm{dia})^{3}$ & & 0,32 & 0,29 & 0,24 & 0,39 & 0,36 & 0,34 & 0,39 \\
\hline Receita (R\$) (RC) por kg de $\mathrm{PCA}^{4}$ & & 3,14 & 3,14 & 3,14 & 3,14 & 3,14 & 3,14 & 3,14 \\
\hline Receita (R\$) do PCA em 112 dias $^{5}$ & & 113,6 & 100,4 & 85,96 & 135,5 & 128,0 & 118,6 & 136,2 \\
\hline Resposta produtiva (RP) $(\mathrm{kg} / \mathrm{kg})^{6}$ & & 0,32 & 0,29 & 0,24 & 0,39 & 0,36 & 0,34 & 0,39 \\
\hline $\operatorname{PMS}(\mathrm{R} \$)^{7}$ & & 1,01 & 0,90 & 0,77 & 1,21 & 1,14 & 1,06 & 1,22 \\
\hline Custo suplemento/animal/dia $(\mathrm{R} \$)^{8}$ & & 1,01 & 0,90 & 0,77 & 1,21 & 1,14 & 1,06 & 1,22 \\
\hline Retorno relativo $(\mathrm{R} \$)^{9}$ & & 1,78 & 1,61 & 1,42 & 2,30 & 2,23 & 2,13 & 2,52 \\
\hline
\end{tabular}

${ }^{a}$ Suplemento mineral; ${ }^{1}$ Níveis de substituição parcial do milho pela glicerina: 0, 10, 20, 30, 40, 50 e $60 \%$, respectivamente. ${ }^{2} \mathrm{Máteria}$ natural; ${ }^{3}$ Ganho diferencial em relação ao animais do suplemento mineral; ${ }^{4}$ Rendimento de carcaça de $52 \%$ e preço da arroba $(15$ $\mathrm{kg})$ de $\mathrm{R} \$ 90,50$, sendo $\mathrm{RC}=(90,50 / 15) * 0,52 ;{ }^{5} \mathrm{Retorno}=(\mathrm{RC} *$ Peso Corporal Adicional $(\mathrm{PCA}) * 112$ dias $) ;{ }^{6} \mathrm{RP}=\mathrm{PCA} /$ consumo de suplemento; ${ }^{7}$ Preço máximo do suplemento $(\mathrm{PMS})=\mathrm{RC} * \mathrm{RP} ;{ }^{8}$ (Consumo de suplemento*PMS); ${ }^{9}$ Retornorelativo em todo o período experimental $=$ Retorno do PCA/custos da suplementação.

Fonte: Elaboração dos autores.

Todos os níveis de substituição parcial do milho pela glicerina proporcionaram retorno relativo positivo (Tabela 5), visto que os custos totais com o fornecimento desses suplementos foram inferiores ao preço máximo do suplemento, acima do qual inviabiliza a suplementação. Deste modo, os ganhos adicionais diários obtidos com a substituição do milho pela glicerina foram efetivos em reduzir os custos diários da suplementação.
O ganho de peso corporal proporcionado pelo fornecimento de suplemento múltiplos com $60 \%$ de substituição do milho pela glicerina (Tabela 4) demonstra a viabilidade econômica (Tabela 5) de se promover abate mais precoce de animais em pastejo no período seco do ano, redirecionando, portanto os gastos com medicamentos, nutrição, recuperação das pastagens, aluguel de pastos, promovendo desocupação das mesmas para outras 
categorias ou para descanso da área e acarretando posteriormente em maior giro do capital.

A partir dos resultados da avaliação econômica foi feito simulações dos possíveis cenários, substituindo o valor da arroba e do suplemento encontrados para cada cenário, gerando assim, seis simulações de viabilidade econômica para cada cenário: melhor, pior, médio, mais provável, otimista e pessimista (Tabelas 6 e 7).
Tabela 6. Cenários dos possíveis preços pagos ao produtor na arroba da vaca e suplemento.

\begin{tabular}{crc}
\hline \multirow{2}{*}{ Cenários } & \multicolumn{2}{c}{ Valores em R\$ } \\
\cline { 2 - 3 } & @ Boi & Suplemento (kg) \\
\hline Melhor & 110,00 & 0,40 \\
Pior & 55,00 & 1,30 \\
Médio & 82,50 & 0,88 \\
Mais provável & 75,00 & 0,80 \\
Otimista & 100,53 & 0,61 \\
Pessimista & 64,47 & 1,14 \\
\hline
\end{tabular}

Fonte: Elaboração dos autores.

Tabela 7. Análises econômicas dos resultados do experimento em função dos cenários simulados referentes à variação nos preços da arroba do boi e do suplemento.

\begin{tabular}{cccccccc}
\hline & \multicolumn{7}{c}{ Lucro $^{1} \mathrm{R} \$$} \\
\cline { 2 - 7 } Cenários & $\mathrm{G} 0^{2}$ & $\mathrm{G} 10^{2}$ & $\mathrm{G} 20^{2}$ & $\mathrm{G} 30^{2}$ & $\mathrm{G} 40^{2}$ & $\mathrm{G} 50^{2}$ & $\mathrm{G} 60^{2}$ \\
\hline Melhor & 112,44 & 99,47 & 82,69 & 144,47 & 135,32 & 123,12 & 143,71 \\
Pior & $-59,79$ & $-66,27$ & $-74,66$ & $-43,77$ & $-48,35$ & $-54,45$ & $-44,16$ \\
Médio & 26,32 & 16,60 & 4,02 & 50,35 & 43,48 & 34,33 & 49,78 \\
Mais provável & 32,63 & 22,61 & 9,64 & 57,38 & 50,31 & 40,88 & 56,79 \\
Otimista & 81,26 & 69,41 & 54,07 & 110,53 & 102,17 & 91,01 & 109,83 \\
Pessimista & $-28,61$ & $-36,21$ & $-46,04$ & $-9,83$ & $-15,20$ & $-22,35$ & $-10,28$ \\
\hline
\end{tabular}

${ }^{1}$ Lucro dos animais suplementados subtraído do lucro dos animais controle ${ }^{2}$ Níveis de substituição parcial do milho pela glicerina: $0,10,20,30,40,50$ e $60 \%$, respectivamente.

Fonte: Elaboração dos autores.

De acordo com os resultados obtidos pode-se considerar que o cenário que mais se aproximou das médias obtidas nesta pesquisa foi o cenário Melhor, devido ao baixo preço do suplemento (média de R\$0,53) e do elevado preço da arroba do boi ( $\mathrm{R} \$ 90,50)$, durante a pesquisa. No entanto, a atividade pode ser considerada como muito sensível a variações de preço.

Os cenários Pior e Pessimistas de todas as estratégias apresentaram resultados negativos, ou seja, o lucro dos animais controle (sal mineral) foi maior do que o dos animais suplementados. Sendo assim, a atividade apresenta incapacidade de pagamento dos custos obtidos com o fornecimento de suplementos.
Contudo, os cenários Melhor e Otimista apresentaram similaridade em relação às médias nesta pesquisa, inferindo-se que nesta ocasião, os preços contribuíram para que a atividade fosse lucrativa de acordo com a avaliação econômica estabelecida.

De acordo com Simões e Moura (2005) este método de avaliação comparativa de diferentes cenários permite fazer inferências sobre possíveis situações futuras. No entanto, não são consideradas todas as possibilidades de ocorrência dos valores para as variáveis de entrada, bem como não se pode prever a probabilidade de ocorrência de cada um deles, ou seja, a análise mostra o que pode ocorrer, mas não "garante" que um dos cenários vai ocorrer. 
A comparação entre os cenários mostram certa oscilação dos resultados, ou seja, positiva quando os cenários foram o Melhor e Otimista, cobrindo os custos com o fornecimento de suplemento com certa margem favorável à atividade, e negativa quando os cenários foram o Pior e o Pessimista, ou seja, nestas ocasiões considera-se desfavorável a atividade, pois os custos com o fornecimento de suplementos são superiores à receita gerada.

Porém, deve-se considerar que esta é uma avaliação econômica referente apenas aos custos com fornecimento de suplemento, e receitas sobre o ganho de peso corporal dos animais obtido no período experimental. Se avaliado em um sistema completo, a suplementação permite maior ganho em arrobas/hectare, redução da idade de abate, aumento da capacidade de suporte da propriedade e da taxa de desfrute do rebanho. Com isso, melhor será a eficiência do empreendimento e maior será o giro do capital.

Além disso, a substituição de uma fonte energética tradicional (milho) pela glicerina serve como alternativa sustentável de reaproveitamento de um dos principais produtos gerados na produção de biodiesel, evitando o acúmulo deste no meio ambiente, com consequente contaminação ambiental (solo e água), colaborando com a preservação dos recursos naturais e com a produção animal sustentável.

\section{Conclusão}

O fornecimento de suplementos múltiplos contendo até $60 \%$ de glicerina para novilhos em pastejo no período da seca proporciona desempenho produtivo e retorno financeiro positivo, demonstrando, portanto o potencial uso de suplementos com inclusão de glicerina para sistemas intensivos de produção de carne bovina em pastejo.

\section{Referências}

CASALI, A. O.; DETMANN, E.; VALADARES FILHO, S. C.; PEREIRA, J.C.; HENRIQUES, L. T.; FREITAS, S. G.; PAULINO, M. F. Influencia do tempo de incubação e do tamanho de partículas sobre os teores de compostos indigestíveis em alimentos e fezes bovinas obtidos por procedimento in situ. Revista Brasileira de Zootecnia, Viçosa, MG, v. 37, n. 2, p. 335-342, 2008.

CERRATE, S.; YAN, F.; WANG, Z.; COTO, C.; SACAKLI, P.; WALDROUP, P. W. Evaluation of glycerine from biodiesel production as a feed ingredient for broilers. International Journal of Poultry Science, Faisalabad, v. 5, n. 11, p. 1001-1007, 2006.

EUCLIDES, V. P. B.; CARDOSO, E. G.; MACEDO, M. C. M.; OLIVEIRA, M. P. Consumo voluntário de Brachiaria decumbens cv. Basilisk e Brachiaria brizantha cv. Marandu sob pastejo. Revista Brasileira de Zootecnia, Viçosa, MG, v. 29, n. 6, p. 2200-2208, 2000.

FARIAS, M. S.; PRADO, I. N.; VALERO, M. V.; ZAWADZKI, F.; SILVA, R. R.; EIRAS, C. E.; RIVAROLI, D. C.; LIMA, B. S. Níveis de glicerina para novilhas suplementadas em pastagens: desempenho, ingestão, eficiência alimentar e digestibilidade. Semina: Ciências Agrárias, Londrina, v. 33, n. 3, p. 1177-1188, 2012.

HALL, M. B. Calculation of non-structural carbohydrate content of feeds that contain non-protein nitrogen. Gainesville: University of Florida, 2000. p. A-25 (Bulletin, 339).

LAMMERS, P. J.; KERR, B. J.; WEBER, T. E.; BREGENDAHL, K.; LONERGAN, S. M.; PRUSA, K. J.; AHN, D. U.; STOFFREGEN, W. C.; DOZIER, W. A.; HONEYMAN, M. S. Growth performance, carcass characteristics, meat quality, and tissue histology of growing pigs fed crude glycerin-supplemented diets. Journal of Animal Science, Champaign, v. 86, n. 11, p. 2962-2970, 2008.

MERTENS, D. R. Regulation of the forage intake. In: FAHEY JUNIOR, G. C.; COLLINS, M.; MERTENS, D. R.; MOSER, L. E. (Ed.). Forage quality evaluation and utilization. Nebraska: American Society of Agronomy, Crop Science of America; Soil Science of America, 1994. p. 450-493.

NATIONAL RESEARCH COUNCIL - NRC. Nutrients requirements of dairy cattle. 7. ed. Washington, D. C.: National Academy Press, 2001. 381 p. 
PARSONS, G. L.; SHELOR, M. K.; DROUILLARD, J. S. Performance and carcass traits of finishing heifers fed crude glycerin. Journal of Animal Science, Champaign, v. 82, n. 2, p. 653-657, 2008.

PAULINO, M. F.; FIGUEIREDO, D. M.; MORAES, E. H. B. K.; PORTO, M. O.; SALES, M. F. L.; ACEDO, T. S.; VILLELA, S. D. J.; VALADARES FILHO, S. C. Suplementação de bovinos em pastagens: uma visão sistêmica. In: SIMPÓSIO DE PRODUÇÃO DE GADO DE CORTE, 4., 2004, Viçosa, MG. Anais... Viçosa, MG: SIMCORTE, 2004. p. 93-144.

REIS, R. A.; MELO, G. M. P.; BERTIPAGLIA, L. M. A.; OLIVEIRA, A. P. Otimização da utilização da forragem disponível através da suplementação estratégica. In: REIS, R. A.; SIQUEIRA, G. R.; BERTIPAGLIA, L. M. A.; OLIVEIRA, A. P.; MELO, G. M. P.; BERNARDES, T. F. (Ed.). Volumosos na produção de ruminantes. Jaboticabal: FUNEP, 2005. p. 187-238.

SAN VITO, E.; BERCHIELLI, T. T.; LAGE, J. F.; CANESIN, R. C.; REIS, R. A.; RIBEIRO JUNIOR, C. S. R.; DELEVATTI, L. M.; MACHADO, M.; DALLANTONIA, E. E.; RIBEIRO, A. F.; SILVA, R. A. Performance of growing Nellore steers on pasture in the dry season fed crude glycerin. Journal of Animal Science, Champaign, v. 90, n. 3, p. 337-342, 2012.

SAUER, F. D.; ERFLE, J. D.; FISHER, L. J. Propylene glycol and glycerol as a feed additive for lactating dairy cows: an evaluation of blood metabolite parameters. Journal of Animal Science, Champaign, v. 53, n. 2, p. 265-271, 1973.

SILVA, D. J.; QUEIROZ, A. C. Análise de alimentos: métodos químicos e biológicos. 3. ed. Viçosa: UFV, 2002. $235 \mathrm{p}$.
SIMÕES, A. R. P.; MOURA, A. D. Análise econômica e de risco para um sistema de recria de gado de corte em regime de pastejo rotacionado na região de Aquidauana MS. In: CONGRESSO DA SOBER, 43., 2005, Ribeirão Preto. Anais... Ribeirão Preto, 2005. CD-ROM.

SNIFFEN, C. J.; BEVERLY, R. W.; MOONEY, C. S.; ROE, M. B.; SKIDMORE, A. L.; BLACK, J. R. Nutrient requirements versus supply in the dairy cow: strategies to account for variability. Journal of Dairy Science, Champaign, v. 76, n. 10, p. 3160-3178, 1993.

SNIFFEN, C. J.; O'CONNOR, J. D.; VAN SOEST, P. J.; FOX, D. G.; RUSSELL, J. B. A net carbohydrate and protein system for evaluating cattle diets: II. Carbohydrate and protein availability. Journal of Animal Science, Champaign, v. 70, n. 11, p. 3562-3577, 1992.

VAN SOEST, P. J. Nutritional ecology of the ruminant. 2. ed. Ithaca: Cornell University, 1994. 476 p.

VAN SOEST, P. J.; ROBERTSON, J. B.; LEWIS, B. A. Symposium: carboydrate metodology, metabolism, and nutritional implications in dairy cattle. Journal of Dairy Science, Champaign, v. 74, n. 10, p. 3583-3597, 1991.

ZERVOUDAKIS, J. T.; SILVA, L. C. R. P.; SILVA, R. P.; JOSÉ NETO, A.; WERNER, J. F. K.; SILVA, R. G. F. Otimização do desempenho de bovinos por meio da suplementação à pasto. In: SIMPÓSIO MATOGROSSENSE DE BOVINOCULTURA DE CORTE, 1., 2011. Cuiabá. Anais... Cuiabá: [s.n.], 2011a. p. 151-189.

ZERVOUDAKIS, J. T.; SILVA, L. C. R. P.; SILVA, R. R.; JOSÉ NETO, A.; KOSCHECK, J. F. W.; SILVA, R. G. F. Resíduos agroindustriais na suplementação de bovinos à pasto. In: SIMPÓSIO DE PECUÁRIA DE CORTE, 7., 2011. Lavras. Anais... Lavras: [s.n.], 2011b. p. 237-313. 
